\title{
Seleção simultânea para qualidade do fruto e resistência à requeima em progênies de tomateiro
}

\author{
Carlos Nick(1), Bruno Soares Laurindo(1), Victor de Souza Almeida(1), Renata Dias de Freitas(1),

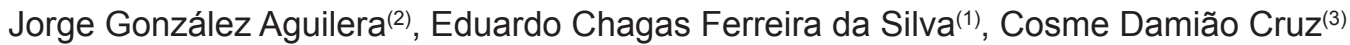 \\ e Derly José Henriques da Silva ${ }^{(1)}$
}

\begin{abstract}
(1) Universidade Federal de Viçosa (UFV), Departamento de Fitotecnia, Avenida P.H. Rolfs, s/no, Campus Universitário, CEP 36570-000 Viçosa, MG. E-mail: carlos.nick@yahoo.com.br, brunoslaurindo@yahoo.com.br, victor.almeida@ufv.br, renataufv08@yahoo.com.br, eduardochagass@gmail.com, derly@ufv.br (2)Embrapa Trigo, Caixa Postal 451, CEP 99001-970 Passo Fundo, RS. E-mail: j51173@yahoo.com ${ }^{(3)}$ UFV, Departamento de Biologia Geral. E-mail: cdcruz@ufv.br
\end{abstract}

Resumo - O objetivo deste trabalho foi avaliar critérios de seleção em progênies de cruzamento entre a cultivar de tomateiro Santa Clara (Solanum lycopersicum) e a espécie silvestre S. habrochaites f. glabratum, quanto a atributos de qualidade dos frutos e de resistência à requeima (Phytophthora infestans). As famílias foram avaliadas em delineamento de blocos ao acaso, em dois ensaios, com duas repetições e seis testemunhas comuns a ambos os ensaios. Ganhos diretos e indiretos foram estimados entre famílias $F_{2: 3}$ para seleção simultânea quanto à resistência à requeima, determinada pela quantificação da área abaixo da curva de progresso da doença (AACPD), e quanto à acidez titulável e aos teores de sólidos solúveis dos frutos. Os critérios de seleção proporcionaram ganhos genéticos satisfatórios, adequados ao ideótipo proposto de decréscimo na AACPD e de incremento nos valores médios de sólidos solúveis e acidez titulável. A seleção direta e indireta e o índice de Mulamba \& Mock resultam em ganhos individuais mais equilibrados e em maiores ganhos totais.

Termos para indexação: Phytophthora infestans, Solanum lycopersicum, germoplasma, índices de seleção, introgressão gênica, recursos genéticos.

\section{Simultaneous selection for fruit quality and resistance to late blight in tomato progenies}

\begin{abstract}
The objective of this work was to evaluate selection criteria in progenies from the crossing of tomato cultivar Santa Clara (Solanum lycopersicum) and the wild species $S$. habrochaites $f$. glabratum as to attributes of fruit quality and of resistance to late blight (Phytophthora infestans). The families were evaluated in a randomized block design, in two trials, with two replicates and six controls, common to both trials. Direct and indirect gains were estimated between $\mathrm{F}_{2: 3}$ families for simultaneous selection regarding resistance to late blight, determined by the quantification of the area under the disease progress curve (AUDPC), and regarding titratable acidity and soluble solid contents of fruit. The selection criteria provided satisfactory genetic gains, suitable for the proposed ideotype of decreases in the AUDPC and increases in the average values of soluble solids and titratable acidity. The direct and indirect selection and the Mulamba \& Mock index result in more balanced individual gains and higher total gains.
\end{abstract}

Index terms: Phytophthora infestans, Solanum lycopersicum, germplasm, selection indexes, gene introgression, genetic resources.

\section{Introdução}

O tomateiro é suscetível a mais de 200 doenças, causadas por fungos, bactérias, nematoides e vírus. No entanto, menos de $10 \%$ dessas doenças acarretam danos econômicos importantes à cultura, com destaque para a mela ou requeima, causada pelo oomiceto Phytophthora infestans (Mont.) de Bary.

Para minimizar perdas ocasionadas por patógenos, genes de resistência, provenientes de germoplasma não adaptado, são introgredidos em Solanum lycopersicum (Abreu et al., 2008; Fiorini et al., 2010; Merk \& Foolad, 2012). Como consequência desse procedimento, vários caracteres indesejáveis são expressos na progênie de cruzamentos entre espécies silvestres e comerciais (Horneburg \& Becker, 2011), o que dificulta a seleção.

É desejável que a seleção quanto à resistência a $P$. infestans, em progênies de tomateiro derivadas de cruzamentos interespecíficos, seja feita simultaneamente à seleção de caracteres de interesse 
agronômico, pois isso pode proporcionar maior eficiência ao processo (Horneburg \& Becker, 2011). No entanto, caracteres de interesse agronômico normalmente têm controle genético complexo, são fortemente influenciados pelo ambiente e, muitas vezes, apresentam correlação entre si (Costa et al., 2004). Assim, para caracteres com herança poligênica, a seleção que considera apenas um caráter de interesse é pouco eficiente, já que pode resultar em um produto final superior apenas em relação a esse caráter (Cruz et al., 2004), o que consumiria grande quantidade de recursos financeiros e de tempo para se chegar ao ideótipo proposto.

A seleção de indivíduos ou famílias de tomateiro com combinações gênicas favoráveis exige que estes reúnam, simultaneamente, características que satisfaçam às exigências de qualidade, por parte do consumidor, e de produtividade e resistência a pragas e doenças, por parte do produtor. Nesse sentido, o uso de índices de seleção que considerem muitas variáveis aumenta a chance de êxito na seleção (Cruz et al., 2004).

Conforme Bhering et al. (2012), o uso de critérios de seleção que permitam a predição dos ganhos genéticos orienta, de maneira mais eficaz, o processo de melhoramento, pois possibilita a previsão dos resultados dos esquemas adotados e a tomada de decisão com base em dados científicos. Entretanto, há escassez de informações relativas à eficácia da seleção simultânea de caracteres relacionados à resistência a doenças e de atributos de qualidade em tomateiro, apesar de esses critérios possibilitarem, por exemplo, a redução do tempo para a obtenção de cultivar-elite.

O objetivo deste trabalho foi avaliar critérios de seleção em progênies de cruzamento entre a cultivar de tomateiro Santa Clara e a espécie silvestre $S$. habrochaites f. glabratum, quanto a atributos de qualidade dos frutos e de resistência à requeima (Phytophthora infestans).

\section{Material e Métodos}

A cultivar suscetível Santa Clara (S. lycopersicum) foi utilizada como genitor feminino no cruzamento com o acesso BGH 6902 (S. habrochaites f. glabratum), resistente a $P$. infestans. O genitor feminino pertence ao grupo Santa Cruz, produz frutos oblongos bi ou triloculares, com peso médio de $130 \mathrm{~g}$, e é consumido in natura. O genitor masculino é uma espécie silvestre, conservada no Banco de Germoplasma de Hortaliças da Universidade Federal de Viçosa (BGH/UFV). $\mathrm{O}$ acesso BGH 6902 produz frutos pequenos, de coloração esverdeada, com sabor e odor desagradáveis. Esse acesso vem sendo utilizado, com frequência, pelo programa de melhoramento do tomateiro da UFV (Abreu et al., 2008; Juhasz et al., 2008; Fiorini et al., 2010; Elsayed et al., 2011), como genitor doador de alelos de resistência.

Parte das plantas $\mathrm{F}_{1}$ foi autofecundada para obtenção da geração $F_{2}$, que, por sua vez, deu origem às 220 famílias $\mathrm{F}_{2: 3}$.

Os experimentos foram instalados na Horta de Pesquisa da UFV, em Viçosa, MG $\left(20^{\circ} 45^{\prime} 14^{\prime \prime S}\right.$ e 42 $52^{\prime} 53^{\prime \prime} \mathrm{W}$, a 648,74 $\mathrm{m}$ de altitude).

As famílias $\mathrm{F}_{2: 3}$ foram avaliadas, em 2010, quanto à resistência à requeima, em dois ensaios. Utilizouse o delineamento em blocos ao acaso, com seis testemunhas - as linhagens $127 \mathrm{f}, 64 \mathrm{~b}, 73 \mathrm{~d}$ e $133 \mathrm{a}$ e os genitores -, comuns a ambos os ensaios.

A semeadura foi realizada em bandejas de poliestireno com 128 células. As bandejas foram mantidas em ambiente protegido até que as plântulas atingissem seis folhas definitivas. As mudas, então, foram transplantadas para o campo, espaçadas de $1 \mathrm{~m}$ entre linhas e $0,60 \mathrm{~m}$ entre plantas. Os tratos culturais foram realizados conforme Guimarães et al. (2007). As parcelas foram compostas por cinco plantas, e as três centrais foram consideradas a parcela útil. No primeiro ensaio, mudas de 119 famílias foram transplantadas para o campo, em 14/6/2010. No segundo ensaio, o transplantio foi realizado em $10 / 8 / 2010$, com uso de 101 famílias.

Para o preparo do inóculo, foram utilizados isolados de $P$. infestans, patogênicos ao tomateiro, provenientes dos municípios Cajuri, Coimbra, Teixeiras e Viçosa, todos localizados na Zona da Mata mineira. O preparo seguiu a metodologia proposta por Abreu et al. (2008), com modificações. Folíolos infectados foram coletados e acondicionados em bandejas de plástico previamente desinfestadas com álcool a $70 \%$, forradas com papel-toalha umedecido em água destilada, e incubados a $18^{\circ} \mathrm{C}$ por 24 horas. Após esse período, lesões foliares com micélio e esporângios foram removidas dos folíolos, e a porção destacada foi colocada em frasco contendo água destilada. Em seguida, a mistura foi agitada em agitador tipo Vortex, para a formação de suspensão de esporângios. 
A concentração das suspensões, provenientes das quatro localidades, foi ajustada com uso de hemacitômetro para $10^{3}$ esporângios por mililitro. As suspensões com concentração ajustada foram misturadas, com uso de volume igual para cada suspensão. A suspensão resultante foi colocada em geladeira com temperatura de aproximadamente $4^{\circ} \mathrm{C}$, por 1 hora, para a formação de zoósporos.

A exposição da progênie ao patógeno ocorreu aos 50 e 65 dias após o transplantio das mudas para o campo, no primeiro e no segundo ensaio, respectivamente. A inoculação foi feita ao entardecer, com o auxílio de pulverizador costal, tendo-se aplicado $30 \mathrm{~mL}$ da suspenção por planta. O tempo decorrido entre o preparo do inóculo e a inoculação não excedeu 2 horas, para evitar a inviabilização dos esporângios. Após a inoculação, os ensaios foram irrigados por microaspersão, três vezes por semana, durante 2 horas, sempre ao entardecer, até o término do período experimental. $\mathrm{O}$ volume de água aplicado em cada irrigação correspondeu à lâmina de $1,25 \mathrm{~mm}$, com irrigação de toda a área experimental. Portanto, essa irrigação teve utilidade apenas como artifício para manter água livre nas folhas, que proporciona condição favorável para germinação dos zoósporos e penetração dos esporos no tecido foliar.

A quantificação da doença foi realizada por meio da avaliação da severidade, em intervalos de dois a três dias, durante 15 dias. A primeira avaliação foi realizada três dias após a inoculação. Dois avaliadores foram treinados por meio do programa Severity Pro (1.0), para realizar as avaliações com maior acurácia. No campo, notas foram atribuídas às folhas de cada planta, conforme escala diagramática proposta por Corrêa et al. (2009). As notas foram utilizadas para estimar a área abaixo da curva de progresso da severidade da requeima (AACPD), segundo Campbell \& Madden (1990), por meio da expressão:

$$
\operatorname{AACPD}=\left[\sum_{\mathrm{i}=1}^{\mathrm{n}-1}\left(\mathrm{y}_{\mathrm{i}}+\mathrm{y}_{\mathrm{i}+1}\right) / 2\right] \times\left(\mathrm{t}_{\mathrm{i}+1}-\mathrm{t}_{\mathrm{i}}\right)
$$

em que $y_{i}$ e $y_{i+1}$ são as percentagens de área foliar lesionada observadas na avaliação i e na seguinte (i+1); $t_{i}$ e $t_{i+1}$ são os intervalos entre as avaliações; e n é número total de observações. Considerou-se como epidemia o tempo decorrido entre a primeira e a última avaliação.

Os valores fenotípicos de cada família foram obtidos por meio da média das notas atribuídas às folhas das três plantas centrais da parcela. Atribuiu-se uma nota final a cada indivíduo das progênies, computada pela média das notas de suas folhas, de acordo com Fiorini et al. (2010).

$\mathrm{O}$ conteúdo de sólidos solúveis ( $\left.{ }^{\circ} \mathrm{Brix}\right)$, determinado com o auxílio de refratômetro portátil Quimis, modelo Q767D (Quimis, Diadema, SP), e a acidez titulável (\% de ácido cítrico), dosada por titulometria, foram obtidos de amostras de cinco frutos, colhidos no segundo ou no terceiro cacho. As avaliações foram realizadas conforme normas analíticas propostas pelo Instituto Adolfo Lutz (2008).

As análises estatísticas foram realizadas por grupos de experimentos, em que foram analisados, conjuntamente, os tratamentos comuns (testemunhas) e os não comuns (famílias), de modo que a comparação entre eles foi feita indistintamente do ensaio em que foram avaliados. Esse procedimento foi adotado em razão do grande número de famílias avaliado, e utilizou-se o Esquema 1 da metodologia proposta por Cruz \& Carneiro (2003). Nesse esquema de análise, os autores recomendam observar as variáveis em que a interação testemunha vs. ensaio é significativa, uma vez que, para a comparação entre duas famílias quaisquer, seus dados devem ser corrigidos por meio do efeito ambiental, calculado a partir das informações das testemunhas. Para que essa correção seja possível, as testemunhas não podem ter comportamento diferente frente às variações ambientais e devem medir apenas a qualidade ambiental (Cruz \& Carneiro, 2003).

Ganhos diretos e indiretos foram estimados nas famílias $\mathrm{F}_{2: 3}$ quanto à resistência à requeima, por meio da obtenção da área abaixo da curva de progresso da requeima, e quanto ao conteúdo de sólidos solúveis e acidez titulável dos frutos. As estimativas de ganhos preditos foram obtidas por meio do estimador: $\mathrm{GS}_{\mathrm{i}}=\mathrm{DS}_{\mathrm{i}} \times \mathrm{h}^{2}$, em que $\mathrm{GS}_{\mathrm{i}}$ é o ganho de seleção direta predito para o caráter i; $\mathrm{DS}_{\mathrm{i}}$ é o diferencial de seleção praticada na população; e $\mathrm{h}^{2}$ é a herdabilidade no sentido amplo. Para a seleção indireta, os ganhos foram estimados com a expressão: $\operatorname{GSi}(\mathrm{j})=\mathrm{DSi}(\mathrm{j}) \times \mathrm{h}^{2}$, em que GSi(j) é o ganho de seleção no caráter i pela seleção no caráter j; DSi(j) é o diferencial de seleção indireta, em que a média dos selecionados é obtida em relação às progênies que apresentam superioridade para a variável auxiliar $\mathrm{j}$; e h ${ }^{2}$ é o coeficiente de herdabilidade da variável principal.

O índice clássico de seleção de Smith (1936) e Hazel (1943) consiste numa combinação linear de vários caracteres de importância econômica, cujos coeficientes de ponderação são estimados de modo que a correlação entre o índice e o agregado genotípico seja maximizada. 
O agregado é estabelecido por outra combinação linear, que envolve os valores genéticos, ponderados pelos respectivos pesos econômicos. Os índices foram estabelecidos segundo o sistema de equações: $\mathrm{Pb}=\mathrm{Ga}$, em que P é a matriz de covariâncias fenotípicas; G é a matriz de covariâncias genotípicas; a é o vetor de pesos econômicos; e b é o vetor de coeficientes do índice de seleção.

O índice proposto por Mulamba \& Mock (1978) baseiase na soma de postos da classificação dos genótipos em relação a cada um dos caracteres avaliados, em ordem favorável ao melhoramento. As ordens de cada material resultam no seguinte índice de seleção: $\mathrm{I}=\mathrm{r}_{1}+\mathrm{r}_{2}+\ldots+\mathrm{r}_{\mathrm{n}}$, em que I é o valor do índice para determinada família; $r_{j}$ é a classificação de uma família em relação ao caráter j; e n é o número de caracteres considerados no índice.

Os pesos econômicos estabelecidos para os caracteres foram o valor 1 , o coeficiente de variação genético e a razão entre o coeficiente de variação genético e experimental $\left(\mathrm{CV}_{\mathrm{g}} / \mathrm{CV}_{\mathrm{e}}\right)$.

\section{Resultados e Discussão}

As condições climáticas entre a inoculação e as avaliações da severidade foram favoráveis ao desenvolvimento do patógeno (Mizubuti, 2005). No primeiro ensaio, entre 5 e 23 de agosto, as temperaturas máxima e mínima foram de 24,8 e $9,9^{\circ} \mathrm{C}$, respectivamente, sem ocorrência de precipitação no período, com umidade relativa de $68,9 \%$. Para o segundo ensaio, as temperaturas registradas foram de 26,9 e $14,4^{\circ} \mathrm{C}$, no período compreendido entre $18 \mathrm{de}$ outubro e 5 de novembro, com umidade relativa de 71,7\% e precipitação de $10,9 \mathrm{~mm}$.

A análise de variância agrupada mostrou que a interação testemunha vs. ensaio não foi significativa para as características fenotípicas avaliadas. O coeficiente de variação experimental estimado para a área abaixo da curva de progresso da requeima foi alto (Tabela 1). Por se tratar de um valor médio entre dois ensaios, essa estimativa pode ser decorrente de oscilações climáticas entre os períodos de avaliação da severidade, em cada ensaio. Contudo, os valores são semelhantes aos relatados por Elsayed (2010). Este autor sugere que coeficientes de variação elevados, para variáveis epidemiológicas, podem ser resultantes das diferenças entre as taxas de progresso da doença nas famílias e da dificuldade em se obter homogeneidade nas notas atribuídas a um mesmo tratamento.

Os valores médios dos coeficientes de variação, para as variáveis de qualidade dos frutos, foram intermediários e concordam com os obtidos por Fiorini (2008).

Tabela 1. Análise de variância conjunta de 220 famílias $F_{2: 3}$ avaliadas, simultaneamente, quanto a caracteres epidemiológicos e de qualidade de frutos.

\begin{tabular}{|c|c|c|c|c|}
\hline \multirow[t]{2}{*}{ Fonte de variação } & \multirow[t]{2}{*}{ GL } & \multicolumn{3}{|c|}{ Quadrados médios } \\
\hline & & $\mathrm{AACPD}^{(1)}$ & Sólidos solúveis ( $\left.{ }^{\circ} \mathrm{Brix}\right)$ & Acidez titulável \\
\hline Blocos & 2 & 951.752 & 3,99 & 0,0049 \\
\hline Ensaios & 1 & 17.109 & 0,56 & 0,0117 \\
\hline Testemunha & 5 & 73.612 & 0,80 & 0,0050 \\
\hline Testemunha vs. Ensaios & 5 & $8.958^{\text {ns }}$ & $0,43^{\text {ns }}$ & $0,0007^{\mathrm{ns}}$ \\
\hline Famílias/Ensaio & 218 & 23.058 & 1,04 & 0,0026 \\
\hline (Testemunha vs. Famílias)/Ensaios & 2 & 130.543 & 2,35 & 0,0049 \\
\hline Resíduo & 230 & 10.812 & 0,83 & 0,0022 \\
\hline Total & 463 & - & - & - \\
\hline $\mathrm{CV}(\%)$ & - & 37,09 & 23,09 & 30,72 \\
\hline
\end{tabular}

${ }^{(1)} \mathrm{AACPD}$, área abaixo da curva de progresso da severidade da requeima. ${ }^{\mathrm{ns}}$ Não significativo.

Tabela 2. Estimativas dos valores médios $\left(\overline{\mathrm{X}}_{0}\right)$, herdabilidade $\left(\mathrm{h}^{2}\right)$ e ganhos de seleção obtidos por meio da seleção direta e indireta em progênie $\mathrm{F}_{2: 3}$, derivada do cruzamento entre Solanum lycopersicum e $S$. habrochaites f. glabratum.

\begin{tabular}{|c|c|c|c|c|c|c|}
\hline \multirow[t]{2}{*}{ Variável } & \multirow[t]{2}{*}{$\overline{\mathrm{X}}_{0}$} & \multirow[t]{2}{*}{$\mathrm{h}^{2}$} & \multicolumn{3}{|c|}{ Ganhos de seleção (\%) } & \multirow[t]{2}{*}{ Total } \\
\hline & & & AACPD & Sólidos solúveis & Acidez titulável & \\
\hline $\mathrm{AACPD}^{(1)}$ & 278,90 & 49,48 & $-31,76$ & 2,14 & 1,03 & $-28,59$ \\
\hline Sólidos solúveis ( $\left.{ }^{\circ} \mathrm{Brix}\right)$ & 3,97 & 16,02 & $-12,39$ & 4,19 & 0,91 & $-7,29$ \\
\hline Acidez titulável & 0,15 & 9,13 & $-10,29$ & 1,68 & 2,99 & $-5,62$ \\
\hline
\end{tabular}

${ }^{(1)} \mathrm{AACPD}$, área abaixo da curva de progresso da severidade da requeima. 
Os métodos de predição de ganhos foram utilizados para que famílias fossem selecionadas segundo um ideótipo, qual seja: menor área abaixo da curva de progresso de $P$. infestans e maiores valores de sólidos solúveis e acidez titulável. O ganho pela seleção direta, em todas as variáveis, foi superior ao proporcionado pela seleção indireta (Tabela 2). Entretanto, os resultados da avaliação conjunta das variáveis foram satisfatórios, uma vez que se constatou, de forma simultânea, acréscimo nos atributos de sólidos solúveis e acidez titulável e decréscimo no valor médio das famílias, independentemente do índice de seleção utilizado. Esse resultado é decorrente de correlações negativas e significativas entre a AACPD e sólidos solúveis $\left(\mathrm{r}=-0,41^{* *}\right)$ e acidez titulável $\left(\mathrm{r}=-0,31^{* *}\right)$, condição favorável à utilização da seleção direta e indireta.

O maior ganho percentual foi verificado no caráter área abaixo da curva de progresso da requeima, que teve maior coeficiente de variação genético $\left(\mathrm{CV}_{\mathrm{g}}\right)$. De acordo com Cruz \& Carneiro (2003), a prática da seleção em situações com alto $\mathrm{CV}_{\mathrm{g}}$ pode ser realizada de forma mais precisa, pois há maior confiabilidade do valor fenotípico médio das famílias em representar seus valores genotípicos. Ganhos superiores proporcionados pela seleção indireta são esperados se a herdabilidade dos caracteres auxiliares for de magnitude superior à do caráter considerado como principal (Falconer, 1987), comportamento não observado no presente trabalho. Santos et al. (2008), em alusão ao estudo de Paula et al. (2002), ressaltaram que o uso de expressões que utilizam o diferencial de seleção para a predição de ganhos resulta em estimativas, no máximo, iguais às obtidas por meio da seleção direta, mas nunca superiores, pois, nessas expressões, são desconsideradas as correlações genéticas e a herdabilidade do caráter auxiliar.

Os índices de seleção, construídos com os pesos econômicos 1, $\mathrm{CV}_{\mathrm{g}}$ e $\mathrm{CV}_{\mathrm{g}} / \mathrm{CV}_{\mathrm{e}}$, proporcionaram distribuição de ganhos negativos para a área abaixo da curva de progresso da requeima e ganhos positivos para sólidos solúveis e acidez titulável, conforme o ideótipo proposto. Os ganhos estimados pelos índices de Smith (1936) e Hazel (1943) e de Mulamba \& Mock (1978), ao se considerar os três pesos econômicos e a área abaixo da curva de progresso da requeima como caráter principal, resultaram em estimativas de ganho total iguais, independentemente do peso econômico utilizado para o índice avaliado (Tabela 3). Em relação aos índices considerados, maior ganho total foi estimado pelo índice de Mulamba \& Mock (1978). Santos et al. (2008) obtiveram melhor resultado com este índice, na estimação de ganhos preditos, quando realizada seleção simultânea quanto à incidência de verrugose e ao vigor em progênies de meios-irmãos de maracujazeiro amarelo, enquanto Costa et al. (2004) observaram resultados similares, em progênies de soja.

Para a área abaixo da curva de progresso da requeima, os ganhos obtidos pelo índice de Smith (1936) e Hazel (1943) foram semelhantes aos estimados por meio da seleção direta, com superioridade do índice para o caráter acidez titulável, mas com menor estimativa de ganho total quando comparado ao ganho predito por meio da seleção direta. Os ganhos preditos pelo índice de Mulamba \& Mock (1978) foram iguais aos conseguidos por meio da seleção direta (Tabelas 2 e 3).

Foi possível obter 50 famílias com uso dos métodos de seleção propostos para a obtenção de ganhos preditos (Tabela 4). Houve coincidência de $100 \%$ entre famílias

Tabela 3. Estimativas dos ganhos de seleção obtidos para as variáveis área abaixo da curva de progresso da severidade da requeima (AACPD), sólidos solúveis e acidez titulável, por meio do uso dos índices de seleção propostos por Smith (1936) e Hazel (1943) e por Mulamba \& Mock (1978), tendo como variável principal a área abaixo da curva de progresso da requeima ${ }^{(1)}$.

\begin{tabular}{lccccc}
\hline Índice & Peso econômico & \multicolumn{3}{c}{ Total } \\
\cline { 3 - 5 } & & AACPD & Sólidos solúveis & Acidez titulável \\
\hline Smith (1936) e Hazel (1943) & 1 & $-30,40$ & 1,99 & 1,61 & $-26,80$ \\
Smith (1936) e Hazel (1943) & $\mathrm{CV}_{\mathrm{g}}$ & $-30,40$ & 1,99 & 1,61 & $-26,80$ \\
Smith (1936) e Hazel (1943) & $\mathrm{CV}_{\mathrm{g}} / \mathrm{CV}_{\mathrm{e}}$ & $-30,40$ & 1,99 & 1,61 & $-26,80$ \\
Mulamba \& Mock (1978) & 1 & $-31,76$ & 2,14 & 1,03 & $-28,59$ \\
Mulamba \& Mock (1978) & $\mathrm{CV}_{\mathrm{g}}$ & $-31,76$ & 2,14 & 1,03 & $-28,59$ \\
Mulamba \& Mock (1978) & $\mathrm{CV}_{\mathrm{g}} / \mathrm{CV}_{\mathrm{e}}$ & $-31,76$ & 2,14 & 1,03 & $-28,59$ \\
\hline
\end{tabular}

${ }^{(1)} \mathrm{AACPD}$, área abaixo da curva de progresso da severidade da requeima; $\mathrm{CV}_{\mathrm{g}}$, coeficiente de variação genético; $\mathrm{CV}_{\mathrm{g}} / \mathrm{CV}_{\mathrm{e}}$, razão entre coeficiente de variação genético e experimental. 
Tabela 4. Estimativas de ganhos genéticos preditos por meio da seleção direta e indireta e dos índices de seleção propostos por Smith (1936) e Hazel (1943) e por Mulamba \& Mock (1978), na seleção de famílias derivadas do cruzamento entre Solanum lycopersicum e $S$. habrochaites f. glabratum.

\begin{tabular}{lcccc}
\hline Seleção & \multicolumn{3}{c}{ Ganhos de seleção (\%) } & \multicolumn{2}{c}{ Famílias selecionadas } \\
\cline { 2 - 4 } & AACPD $^{(1)}$ & Sólidos solúveis & Acidez titulável & \\
\hline Direta e indireta & $-31,76(99,90)$ & $2,14(4,50)$ & $1,03(0,17)$ & 115355327571016231552981122194132622635661093694 \\
& & & & 85148171171075911930201189044168318997392651111210 \\
Smith (1936) e Hazel (1947) & $-30,40(107,45)$ & $1,99(4,47)$ & $1,61(0,18)$ & 51153575527848314109118532113291079499101621110031 \\
& & & & 44268118562856959119229111112610908496637202202812 \\
Mulamba \& Mock (1978) & $-26,856(127,55)$ & $3,37(4,81)$ & $1,19(0,17)$ & 115355327571016231552981122194132622635661093694 \\
& & & & 85148171171075911930201189044168318997392651111210 \\
\hline Média das famílias & 284,46 & 4,19 & 0,15 & \\
\hline
\end{tabular}

${ }^{(1)} \mathrm{AACPD}$, área abaixo da curva de progresso da severidade da requeima.

selecionadas por meio da seleção direta e indireta e as selecionadas pelo índice de Mulamba \& Mock (1978). Essa coincidência, para o índice de Smith (1936) e Hazel (1943), foi de 86\%.

\section{Conclusões}

1. Ganhos genéticos satisfatórios, adequados ao ideótipo proposto de decréscimo na área abaixo da curva de progresso da requeima e aumento nos valores de sólidos solúveis e acidez titulável, podem ser obtidos por meio dos critérios de seleção utilizados em progênies de tomateiro.

2. A seleção direta e indireta e o índice de Mulamba \& Mock resultam em ganhos individuais mais equilibrados e em maiores ganhos totais em progênies de tomateiro.

\section{Agradecimentos}

À Fundação de Amparo à Pesquisa do Estado de Minas Gerais (Fapemig) e à Universidade Federal de Viçosa, pelo apoio financeiro; e ao Conselho Nacional de Desenvolvimento Científico e Tecnológico (CNPq) e à Coordenação de Aperfeiçoamento de Pessoal de Nível Superior (Capes), pela concessão de bolsa.

\section{Referências}

ABREU, F.B.; SILVA, D.J.H. da; CRUZ, C.D.; MIZUBUTI, E.S.G. Inheritance of resistance to Phytophthora infestans (Peronosporales, Pythiaceae) in a new source of resistance in tomato (Solanum sp.) (formerly Lycopersicon sp.), Solanales, Solanaceae). Genetics and Molecular Biology, v.31, p.493-497, 2008. DOI: $10.1590 /$ S1415-47572008000300016.
BHERING, L.L.; LAVIOLA, B.G.; SALGADO, C.C.; BARRERA SANCHEZ, C.F.; ROSADO, T.B.; ALVES, A.A. Genetic gains in physic nut using selection indexes. Pesquisa Agropecuária Brasileira, v.47, p.402-408, 2012. DOI: 10.1590/S0100204X2012000300012.

CAMPBELL, C.L.; MADDEN, L.V. Introduction to plant disease epidemiology. New York: John Wiley, 1990. 532p.

CORRÊA, F.M.; BUENO FILHO, J.S.S.; CARMO, M.G.F. Comparison of three diagrammatic keys for the quantification of late blight in tomato leaves. Plant Pathology, v.58, p.1128-1133, 2009. DOI: 10.1111/j.1365-3059.2009.02140.x.

COSTA, M.M.; DI MAURO, A.O.; UNÊDA-TREVISOL, S.H.; ARRIEL, N.H.C.; BÁRBARO, I.M.; MUNIZ, F.R.S. Ganho genético por diferentes critérios de seleção em populações segregantes de soja. Pesquisa Agropecuária Brasileira, v.39, p.1095-1102, 2004. DOI: 10.1590/S0100-204X2004001100007.

CRUZ, C.D.; CARNEIRO, P.C.S. Modelos biométricos aplicados ao melhoramento genético. Viçosa: UFV, 2003. 585p.

CRUZ, C.D.; REGAZZI, A.J.; CARNEIRO, P.C.S. Modelos biométricos aplicados ao melhoramento genético. Viçosa: UFV, 2004. 375p.

ELSAYED, A.Y.; SILVA HENRIQUES, H. da; MIZUBUTI, E.S.G.; CARNEIRO, C.P. Combing the monogenic and polygenic resistant genes to late blight in tomato. Journal of Plant Breeding and Crop Science, v.3, p.251-259, 2011.

ELSAYED, A.Y.A.M. Inheritance of resistance to tomato late blight in a population of Solanum lycopersicum $\times$ Solanum habrochaites. 2010. 88p. Tese (Doutorado) - Universidade Federal de Viçosa, Viçosa.

FALCONER, D.S. Introdução à genética quantitativa. Viçosa: UFV, 1987. 279p.

FIORINI, C.V.A. Introgressão de genes de resistência à requeima de Solanum habrochaites em Solanum lycopersicum. 2008. 163p. Tese (Doutorado) - Universidade Federal de Viçosa, Viçosa.

FIORINI, C.V.A.; SILVA, D.J.H. da; MIZUBUTI, E.S.G.; BARROS, J. de S.; SILVA, L.J. da; MILAGRES, C.; ZAPAROLI, M.R. Caracterização de linhagens de tomateiro originadas de 
cruzamento interespecífico quanto à resistência à requeima. Horticultura Brasileira, v.28, p.197-202, 2010. DOI: 10.1590/ S0102-05362010000200010.

GUIMARÃES, M.A.; CALIMAM, F.R.B.; SILVA, D.J.H.; MARIM, B.G.; SOUZA, J.B. Tratos culturais do tomateiro. In: SILVA, D.J.H.; VALE, F.X.R. (Ed.). Tomate: tecnologia de produção. Visconde do Rio Branco: Suprema Gráfica, 2007. p.85-99.

HAZEL, L.N. The genetic basis for constructing selection indexes. Genetics, v.28, p.476-490, 1943.

HORNEBURG, B.; BECKER, H.C. Selection for Phytophthora field resistance in the $\mathrm{F}_{2}$ generation of organic outdoor tomatoes. Euphytica, v.180, p.357-367, 2011. DOI: 10.1007/s10681-0110384-3.

INSTITUTO ADOLFO LUTZ. Métodos fisíco-químicos para análise de alimentos. São Paulo: Instituto Adolfo Lutz, 2008. $1020 \mathrm{p}$.

JUHÁSZ, A.C.P.; SILVA, D.J.H. da; ZERBINI JUNIOR, F.M.; CARNEIRO, P.C.S.; SOARES, B.O.; CRUZ, C.D. Base genética da resistência de um acesso de tomate silvestre ao mosaicoamarelo do pimentão. Pesquisa Agropecuária Brasileira, v.43, p.713-720, 2008. DOI: 10.1590/S0100-204X2008000600007.
MERK, H.L.; FOOLAD, M.R. Parent-offspring correlation estimate of heritability for late blight resistance conferred by an accession of the tomato wild species Solanum pimpinellifolium. Plant Breeding, v.131, p.203-210, 2012. DOI: 10.1111/j.14390523.2011.01898.x.

MIZUBUTI, E.S.G. Custo da requeima. Cultivar: Hortaliças e Frutas, v.32, p.23-26, 2005.

MULAMBA, N.M.; MOCK, J.J. Improvement of yield potential of the Eto Blanco maize (Zea mays L.) population by breeding for plant traits. Egyptian Journal of Genetics and Cytology, v.7, p.40-51, 1978.

PAULA, R.C. de; PIRES, I.E.; BORGES, R. de C.G.; CRUZ, C.D. Predição de ganhos genéticos em melhoramento florestal. Pesquisa Agropecuária Brasileira, v.37, p.159-165, 2002. DOI: 10.1590/S0100-204X2002000200007.

SANTOS, C.E.M. dos; PISSIONI, L.L.M.; MORGADO, M.A.D.; CRUZ, C.D.; BRUCKNER, C.H. Estratégia de seleção em progênies de maracujazeiro-amarelo quanto ao vigor e incidência de verrugose. Revista Brasileira Fruticultura, v.30, p.444-449, 2008. DOI: 10.1590/S0100-29452008000200030.

SMITH, H.F. A discriminant function for plant selection. Annals of Human Genetics, v.7, p.240-250, 1936. DOI: 10.1111/j.14691809.1936.tb02143.x.

Recebido em 2 de abril de 2012 e aprovado em 28 de dezembro de 2013 